\title{
Article \\ Electrochemistry, Electrodeposition, and Photoluminescence of Eu (III)/Lanthanides (III) on Terpyridine-Functionalized Ti Nanospikes
}

\author{
Min Hee Joo ${ }^{1,2}$, So Jeong Park ${ }^{1}$, Hye Ji Jang ${ }^{1}$, Sung-Min Hong ${ }^{1,2}$, Choong Kyun Rhee ${ }^{1}$ and Youngku Sohn ${ }^{1,2, * \mathbb{D}}$ \\ 1 Department of Chemistry, Chungnam National University, Daejeon 34134, Korea; \\ 202050113@o.cnu.ac.kr (M.H.J.); jsjs5921@naver.com (S.J.P.); gpw19325@o.cnu.ac.kr (H.J.J.); \\ qwqe212@o.cnu.ac.kr (S.-M.H.); ckrhee@cnu.ac.kr (C.K.R.) \\ 2 Department of Chemical Engineering and Applied Chemistry, Chungnam National University, \\ Daejeon 34134, Korea \\ * Correspondence: youngkusohn@cnu.ac.kr; Tel.: +82-42-821-6548
}

check for updates

Citation: Joo, M.H.; Park, S.J.; Jang, H.J.; Hong, S.-M.; Rhee, C.K.; Sohn, Y. Electrochemistry,

Electrodeposition, and

Photoluminescence of Eu

(III) / Lanthanides (III) on

Terpyridine-Functionalized $\mathrm{Ti}$

Nanospikes. Metals 2021, 11, 977.

https://doi.org/10.3390/met11060977

Academic Editor: Petros E. Tsakiridis

Received: 24 May 2021

Accepted: 15 June 2021

Published: 18 June 2021

Publisher's Note: MDPI stays neutral with regard to jurisdictional claims in published maps and institutional affiliations.

Copyright: (c) 2021 by the authors. Licensee MDPI, Basel, Switzerland. This article is an open access article distributed under the terms and conditions of the Creative Commons Attribution (CC BY) license (https:/ / creativecommons.org/licenses/by/ $4.0 /)$.

\begin{abstract}
Terpyridine-functionalized Ti nanospike electrodes (TiNS-SiTpy) were developed and applied to cyclic voltammetry and amperometry of Ln ( $\mathrm{La}, \mathrm{Ce}, \mathrm{Pr}, \mathrm{Nd}, \mathrm{Sm}, \mathrm{Eu}, \mathrm{Gd}, \mathrm{Tb}, \mathrm{Dy}, \mathrm{Ho}, \mathrm{Er}$, $\mathrm{Tm}$, and $\mathrm{Yb}$ ) ions and mixed $\mathrm{Eu}(\mathrm{III})+\mathrm{Ln}(\mathrm{III})$ ions in a $0.1 \mathrm{M} \mathrm{NaClO}_{4}$ electrolyte. Electrodeposition was successfully performed over TiNS-SiTpy electrodes, which were fully examined by scanning electron microscopy, X-ray diffraction crystallography, Fourier-transform infrared spectroscopy, energy dispersive $\mathrm{X}$-ray spectroscopy, $\mathrm{X}$-ray photoelectron spectroscopy, photoluminescence (PL), and PL decay kinetics. The Gd and Tb ions were found to increase PL intensities with $10 \times$ longer lifetimes of $1.32 \mu \mathrm{s}$ and $1.03 \mu \mathrm{s}$, respectively, compared with that of the electrodeposited Eu sample. The crystal phase and the oxidation states were fully examined for the mixed $\mathrm{Ln}(\mathrm{Eu}+\mathrm{Gd}$ and Eu + $\mathrm{Tb}$ ) complex structures.
\end{abstract}

Keywords: lanthanide; Ti nanospike; electrodeposition; cyclic voltammetry; amperometry; photoluminescence

\section{Introduction}

Lanthanide ( $\mathrm{Ln}$ ) elements have very usefully appeared in diverse application fields such as display industry, magnets, bio industry, pyroprocessing technology in nuclear power plants, and energy/environment fields [1-10]. The Ln elements have very unique and similar physicochemical properties because of electronic configurations in $4 \mathrm{f}$-block in the periodic table. To achieve better roles of Ln elements, the studies on Ln elements include Ln coordination chemistry, electrochemical Ln redox reactions, luminescent materials, and selective recovery (for recycling of precious elements) by electrodeposition [11-23]. Bejan et al. synthesized three-dimensional Ln-organic frameworks of $\left[\mathrm{LnL}\left(\mathrm{H}_{2} \mathrm{O}\right)_{2}\right]_{n} \cdot \mathrm{DMF} \cdot \mathrm{yH} \mathrm{H}_{2} \mathrm{O}$ with a surface area of about $400 \mathrm{~m}^{2} / \mathrm{g}$ by the solvothermal method and demonstrated as a catalyst in acylation reaction of 2-naphthol with acetic anhydride [11]. Lu et al. synthesized $\mathrm{Tb}$ (III) and Eu (III)-organic complex-doped silica nanoparticles with high luminescent properties and embedded in transparent membranes by the electrospinning method for their applications to fluorescent clothing, counterfeiting, and labels [14]. Fan et al. synthesized monodispersed $\alpha-\mathrm{NaYF}_{4}: \mathrm{RE}^{3+}(\mathrm{RE}=\mathrm{Eu}, \mathrm{Tb}, \mathrm{Ce}, \mathrm{Er}$, and Tm) colloidal spheres and achieved multi-color emissions with orange-red, green, UV emission, bluegreen, and blue depending on the excitation wavelength [17]. They also applied the spheres to in vitro cell imaging. Joo et al. have demonstrated electrodeposition of Ln elements on diverse electrodes such as carbon, $\mathrm{Ni}$, and porous $\mathrm{Si}$, and showed that $\mathrm{Ln}$ elements were successfully recovered on the electrodes [21-23].

The main purpose of this study was to examine electrochemical behaviors in mixed Ln ions in an electrolyte and electrodeposit the elements on a Ti nanospike electrode in 
view of recycling of precious elements and nanomaterial preparations. Eu (III) was chosen as a common ion in mixed Ln ions because it has been extensively used as a luminescence probe as well as hypersensitivity in the local coordination environment [24,25]. Gd (III) and $\mathrm{Tb}$ (III) as mixed ions were mainly selected for full characterization because they showed much higher luminescent properties than other electrodeposited materials prepared in other mixed Ln (III) ions. Terpyridine (Tpy)-functionalized Ti electrode was chosen because Tpy has three $\mathrm{N}$ atoms and acts as a Lewis basic ligand [26-28]. Therefore, the ligand may strongly interact with Lewis acidic Ln (III) ions at the electrode and electrolyte interface. Consequently, the electrochemistry and electrodeposition will be altered by the surface modification. The nanospike structure was developed to further increase contact areas between metal ions and the electrode surface. The newly developed electrode system and the new electrochemical tests provide valuable information on understanding Ln elements for their diverce applications in displays, bio industry, pyroprocessing technology, and energy/environment materials.

\section{Materials and Methods}

Chemicals used in this study were (3-aminopropyl)trimethoxysilane (APTMS, 97\%, Sigma-Aldrich, Saint Louis, MO, USA), 2,2':6',2' $2^{\prime \prime}$-terpyridine- $4^{\prime}$-carboxylic acid (Tpy$\mathrm{COOH}, 95 \%$, Alfar Aesar, Ward Hill, MA, USA), La (III) nitrate hexahydrate (99.999\%, Sigma-Aldrich), Dimethyl sulfoxide (anhydrous, $\geq 99.9 \%$, Sigma-Aldrich), Ce (III) nitrate hexahydrate (99\%, Sigma-Aldrich), Pr (III) nitrate pentahydrate (99.9\%, Alfa Aesar), Nd (III) nitrate hexahydrate (99.9\%, Alfa Aesar), Sm (III) nitrate hexahydrate (99.9\%, Alfa Aesar), Eu (III) nitrate hexahydrate (99.9\%, Alfa Aesar), Gd (III) nitrate hexahydrate (99.9\%, Sigma-Aldrich), Tb (III) nitrate hydrate (99.9\%, Alfa Aesar), Dy (III) nitrate pentahydrate (99.9\%, Sigma-Aldrich), Ho (III) nitrate pentahydrate (99.99\%, Alfa Aesar), Er (III) nitrate hydrate (99.9\%, Sigma-Aldrich), Tm (III) nitrate hydrate (99.9\%, Alfa Aesar), and Yb (III) nitrate hydrate $(99.9 \%$, Sigma Aldrich).

Titanium $(\mathrm{Ti})$ sheets $(5 \mathrm{~mm} \times 20 \mathrm{~mm})$ were cleaned by sonication in acetone, isopropyl alcohol, and water repeatedly. After that, the cleaned Ti sheets were dipped in a $1 \% \mathrm{HF}$ solution for $30 \mathrm{~min}$. Then, a nanospike morphology was finally achieved. For surface functionalization with terpyridine group, Ti nanospikes (abbreviated as TiNS) were first dipped in $\mathrm{H}_{2} \mathrm{O} / \mathrm{NH}_{3}$ (aq. $25.0-30.0 \%$ ) $/ \mathrm{H}_{2} \mathrm{O}_{2}$ (aq. 34.5\%) $(5: 3: 1, v / v)$ solution at $60{ }^{\circ} \mathrm{C}$ for $1 \mathrm{~h}$, rinsed with deionized water, and dried under $\mathrm{N}_{2}$ gas blowing. The $\mathrm{OH}$-terminated TiNS substrate was dipped in methanol with 1\% APTMS for $12 \mathrm{~h}$, rinsed with methanol, and dried under $\mathrm{N}_{2}$ gas blowing. The APTMS-functionalized TiNS substrate was then dipped in a $1 \mathrm{mM}$ Tpy-COOH/DMSO solution for $6 \mathrm{~h}$, rinsed with pure DMSO solvent, and dried under $\mathrm{N}_{2}$ gas blowing. The details of the functionalization procedure are described elsewhere [26-28]. Consequently, terpyridine-functionalized TiNS was achieved and abbreviated as TiNS-SiTpy.

Electrochemical experiments of cyclic voltammetry $(\mathrm{CV})$ and amperometry were performed in a three-electrode system (a working, a Pt wire counter, and a $\mathrm{Ag} / \mathrm{AgCl}$ reference electrodes) using a ZIVE SP 1 Potentiostat/Galvanostat/EIS (WonATech Co., Ltd. Seoul, Korea). For the electrochemistry of a single Ln element, the concentration of Ln ions was $10 \mathrm{mM}$ in a $0.1 \mathrm{M} \mathrm{NaClO}_{4}$ supporting electrolyte. For the electrochemistry of mixed $\mathrm{Ln}$ ions (Eu and another $\mathrm{Ln})$, the concentrations were $5 \mathrm{mM}(\mathrm{Eu})$ and $5 \mathrm{mM}(\mathrm{Ln})$, respectively, in a $0.1 \mathrm{M} \mathrm{NaClO}_{4}$ electrolyte. The $\mathrm{CV}$ was performed between $-1.8 \mathrm{~V}$ and $+0.5 \mathrm{~V}$ (vs. $\mathrm{Ag} / \mathrm{AgCl}$ ). The fixed potential for amperometry was based on the CV profiles and amperometry electrodeposition was performed for $2 \mathrm{~h}$. After the electrodeposition, the electrode samples were gently washed with deionized water and dried under an IR lamp.

The morphology of the electrodeposited samples was examined using a Hitachi SE4800 field emission scanning electron microscope (FE-SEM, Hitachi Ltd., Tokyo, Japan) with an operating voltage of $10 \mathrm{kV}$. Optical microscope images $(300 \times$ amplification) were also obtained to confirm the electrodeposition using a EG Tech EGVM-452M video microscope system (EG Tech., Gyounggi, Korea). Elemental composition of the electrodeposited 
samples was evaluated by energy dispersive $\mathrm{X}$-ray spectroscopy (EDXS) analysis using a TESCAN LYRA3 XMU focused ion beam-SEM (Brno, Czech Republic). Fourier-transform infrared (FT-IR) spectra were obtained using a Thermo Scientific Nicolet iS10 spectrometer (Thermo Scientific Korea, Seoul, Korea) with attenuated total reflectance mode. Photoluminescence (PL) emission spectra of the electrodeposited samples were taken using a AvaSpec spectrometer (model ULS2048CL-EVO-RS, Louisville, CO, USA) equipped with a high-power deuterium halogen lamp (model AvaLight-DH-S-BAL, Louisville, CO, USA). 2D and 3D PL profiles were obtained using a Fluorescence spectrometer (FS-2, Scinco, Seoul, Korea) equipped with a $150 \mathrm{~W}$ Xe lamp. PL decay profiles were obtained using a FluoroLog 3 spectrometer (Horiba-Jobin Yvon, Kyoto, Japan) with a single photon counting photomultiplier tub and a pulsed laser diode $374 \mathrm{~nm}( \pm 10)$. The crystal phases of the electrodeposited samples were investigated by $\mathrm{X}$-ray diffraction crystallography using a MiniFlex II powder X-ray diffractometer (Rigaku Corp., Tokyo, Japan, CNU chemistry core-facility) with $\mathrm{Cu} K \alpha$ radiation. The chemical states of the electrodeposited samples were examined by X-ray photoelectron spectroscopy (XPS) using a Thermo-VG Scientific $\mathrm{K}$-alpha ${ }^{+}$spectrometer (Waltham, MA, USA) with a hemispherical energy analyzer and a monochromatic $\mathrm{Al} K \alpha \mathrm{X}$-ray source.

\section{Results and Discussion}

Figure 1 shows the cyclic voltammetry curves (initial cycle) at a scan rate of $0.2 \mathrm{~V} / \mathrm{s}$ over TiNS-SiTpy electrodes in $5 \mathrm{mM} \mathrm{Eu}$ (III) $+5 \mathrm{mM} \mathrm{Ln}$ (III) $/ 0.1 \mathrm{M} \mathrm{NaClO}_{4}$ electrolytes, compared with the $\mathrm{CV}$ profiles in a blank $0.1 \mathrm{M} \mathrm{NaClO}_{4}, 10 \mathrm{mM} \mathrm{Ln} \mathrm{(III)/0.1} \mathrm{M} \mathrm{NaClO}_{4}$, and $10 \mathrm{mM} \mathrm{Eu}$ (III) $/ 0.1 \mathrm{M} \mathrm{NaClO}_{4}$ electrolytes. For a single Ln element, cyclic voltammetry profiles were also obtained at $0.2 \mathrm{~V} / \mathrm{s}$ over bare TiNS and TiNS-SiTpy electrodes in a $10 \mathrm{mM}$ $\mathrm{Ln}$ (III) $/ 0.1 \mathrm{M} \mathrm{NaClO}_{4}$ electrolyte and are provided in the Supplemental Materials Figure S1 and Figure S2, respectively. In a blank $0.1 \mathrm{M} \mathrm{NaClO}_{4}$ electrolyte, the $\mathrm{CV}$ profile (dotted gray line) between $+0.5 \mathrm{~V}$ and $-1.8 \mathrm{~V}$ (vs. $\mathrm{Ag} / \mathrm{AgCl}$ ) showed no meaningful redox peaks, except a sharp current increase (starting from $-0.8 \mathrm{~V}$ during the negative-going scan) due to the hydrogen evolution reaction [21-23]. Upon addition of Ln (III) ions, the CV profile became meaningfully changed and a new curvature appeared between $-0.9 \mathrm{~V}$ and $-1.5 \mathrm{~V}$. In $5 \mathrm{mM} \mathrm{Eu}$ (III) $+5 \mathrm{mM} \mathrm{La}$ (III) $/ 0.1 \mathrm{M} \mathrm{NaClO}_{4}$ electrolyte (Figure 1a), a curvature (or a CV peak) appeared around $-1.25 \mathrm{~V}$ (vs. $\mathrm{Ag} / \mathrm{AgCl}$ ). Other $\mathrm{CV}$ profiles (Ce, $\mathrm{Pr}, \mathrm{Nd}, \mathrm{Sm}, \mathrm{Gd}, \mathrm{Tb}$, $\mathrm{Dy}, \mathrm{Ho}, \mathrm{Er}, \mathrm{Tm}$, and $\mathrm{Yb}$ mixed Eu ions) showed the curvature between $-1.4 \mathrm{~V}$ and $-1.2 \mathrm{~V}$. The peak position $( \pm 0.01 \mathrm{~V})$ was determined by the intersection point of the two crossing lines as depicted in the corresponding CV profile in Figure 1. Joo et al. also observed similar CV profiles for $\mathrm{Ln}$ (III) ions on carbon, $\mathrm{Ni}$, and porous Si electrodes [21-23]. There was a weak inclination that the $\mathrm{CV}$ peak became slightly shifted to a positive direction, as shown in Figure 1n. This is plausibly due to sizes of lanthanide ions, known as lanthanide contraction, where the size is known to be decreased as the atomic number increases from $\mathrm{La}$ (No. 57) to $\mathrm{Yb}$ (No. 70) [21-23]. For Eu (III) ions, the CV peak position was observed to be around $-0.9 \mathrm{~V}$, about $-0.3 \mathrm{~V}$ lower than other $\mathrm{Ln}$ (III) ions. It is possible that the reduction $\left(\mathrm{Eu}^{3+}+\mathrm{e}^{-} \rightarrow \mathrm{Eu}^{2+}\right)$ of free $\mathrm{Eu}$ (III) ion was involved in this region [21-23]. 

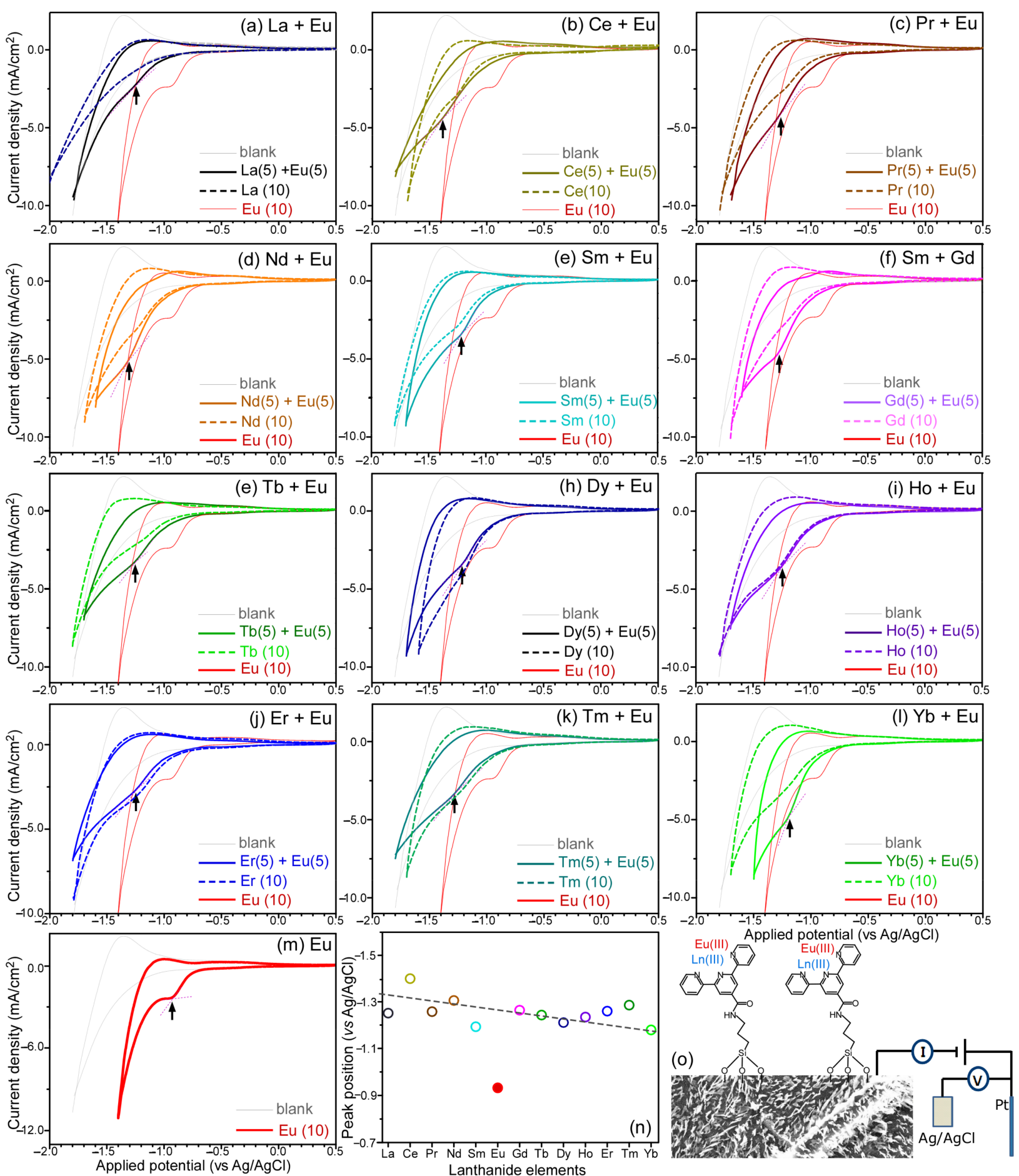

Figure 1. Superimposed cyclic voltammetry profiles (a-m) at $0.2 \mathrm{~V} / \mathrm{s}$ over TiNS-SiTpy electrodes in a blank $0.1 \mathrm{M} \mathrm{NaClO}_{4}$ (thin gray lines), $5 \mathrm{mM} \mathrm{Eu}(\mathrm{III})+5 \mathrm{mM} \mathrm{Ln} \mathrm{(III)} / 0.1 \mathrm{M} \mathrm{NaClO}_{4}$ (thick lines), $10 \mathrm{mM} \mathrm{Ln} \mathrm{(III)/0.1} \mathrm{M} \mathrm{NaClO}_{4}$ (broken lines), and $10 \mathrm{mM} \mathrm{Eu}(\mathrm{III}) / 0.1 \mathrm{M} \mathrm{NaClO}_{4}$ (red lines) electrolytes, the new peak positions (V vs. $\mathrm{Ag} / \mathrm{AgCl}$ ) with mixed Ln ions (n), and a schematic of the three electrode electrochemical system with a TiNS-SiTpy electrode (o). Each arrow indicates the intersection point of two crossing lines.

For the CV profiles over bare TiNS electrodes in unmixed (pure) Ln (III) ions of $10 \mathrm{mM}$ $\mathrm{Ln}$ (III) $/ 0.1 \mathrm{M} \mathrm{NaClO}_{4}$ electrolyte, as displayed in the Supplemental Materials Figure S1, the $\mathrm{CV}$ peak for $\mathrm{La}$ (III) ion was observed around $-1.5 \mathrm{~V}$ (vs. $\mathrm{Ag} / \mathrm{AgCl}$ ), and the potential was 
observed at $-1.35 \mathrm{~V}$ for $\mathrm{Yb}$ (III) ion. Except for the $\mathrm{Eu}$ (III) ion, the CV peak was observed between $-1.5 \mathrm{~V}$ and $-1.3 \mathrm{~V}$ for other Ln ions. For the CV profiles over bare TiNS-SiTpy electrodes in a $10 \mathrm{mM} \mathrm{Ln}$ (III) $/ 0.1 \mathrm{M} \mathrm{NaClO}_{4}$ electrolyte, as displayed in the Supplemental Materials Figure S2, except for the Eu (III) and La (III) ions, the CV peak was observed between $-1.3 \mathrm{~V}$ and $-1.15 \mathrm{~V}$ for other Ln ions. Generally, the functionalized electrodes showed lower negative potentials. The functionalized terpyridine appears to play a role in the electrochemical behavior, as depicted in Figure 1o. Joo et al. performed CV using plain Ti and Ti-SiTpy sheets in a $10 \mathrm{mM}$ Ln (III)/0.1 $\mathrm{M} \mathrm{NaClO}_{4}$ electrolyte. They observed that $\mathrm{CV}$ peaks were observed between $-1.6 \mathrm{~V}$ and $-1.4 \mathrm{~V}$ (vs. $\mathrm{Ag} / \mathrm{AgCl}$ ) and between $-1.5 \mathrm{~V}$ and $-1.2 \mathrm{~V}$ (vs. Ag/AgCl) in plain Ti and Ti-SiTpy sheets, respectively [28]. Compared with the present study (Supplemental Materials, Figures S1 and S2), the nanospike structure showed lower negative potentials than those for the plain Ti surfaces.

Electrodeposition of the Ln (III) species was performed by the amperometry method in a $5 \mathrm{mM} \mathrm{Eu}$ (III) $+5 \mathrm{mM} \mathrm{Ln}$ (III) $/ 0.1 \mathrm{M} \mathrm{NaClO}_{4}$ electrolyte at a fixed applied potential for $2 \mathrm{~h}$. The applied potentials $(\mathrm{La}+\mathrm{Eu}:-1.2 \mathrm{~V}, \mathrm{Ce}+\mathrm{Eu}:-1.4 \mathrm{~V}, \mathrm{Pr}+\mathrm{Eu}:-1.3 \mathrm{~V}, \mathrm{Nd}+\mathrm{Eu}$ : $-1.3 \mathrm{~V}, \mathrm{Sm}+\mathrm{Eu}:-1.2 \mathrm{~V}, \mathrm{Eu}:-1.2 \mathrm{~V}, \mathrm{Gd}+\mathrm{Eu}:-1.3 \mathrm{~V}, \mathrm{~Tb}+\mathrm{Eu}:-1.2 \mathrm{~V}, \mathrm{Dy}+\mathrm{Eu}:-1.2 \mathrm{~V}$, $\mathrm{Ho}+\mathrm{Eu}:-1.2 \mathrm{~V}, \mathrm{Er}+\mathrm{Eu}:-1.3 \mathrm{~V}, \mathrm{Tm}+\mathrm{Eu}:-1.3 \mathrm{~V}, \mathrm{Yb}+\mathrm{Eu}:-1.2 \mathrm{~V}$ ) were based on the $\mathrm{CV}$ profiles and the peak positions seen in Figure 1n. As seen in the selected superimposed CV profiles taken in $10 \mathrm{mM} \mathrm{Eu}$ (III)/0.1 $\mathrm{M} \mathrm{NaClO}_{4}, 5 \mathrm{mM} \mathrm{Ln}$ (III)+5 mM Eu (III)/0.1 $\mathrm{M} \mathrm{NaClO}_{4}$, and $10 \mathrm{mM} \mathrm{Ln} \mathrm{(III)/0.1} \mathrm{M} \mathrm{NaClO}_{4}$ electrolytes (Supplemental Materials Figure S3), the CV profiles in the mixed ions ( $5 \mathrm{mM} \mathrm{Eu}$ (III) $+5 \mathrm{mM} \mathrm{Gd}$ (III) or $5 \mathrm{mM} \mathrm{Eu}$ (III) $+5 \mathrm{mM}$ Tb (III)) showed stronger $\mathrm{CV}$ peaks (marked by an up arrow, $\uparrow$ ) compared with those in $10 \mathrm{mM} \mathrm{Eu}$ (III)/0.1 $\mathrm{M} \mathrm{NaClO}_{4}$ and $10 \mathrm{mM} \mathrm{Ln} \mathrm{(III)/0.1} \mathrm{M} \mathrm{NaClO}_{4}$ electrolytes. This indicates that the newly enhanced signal was associated with the electrodeposition signal. The CV signal volume was increased and the peak position was shifted to a higher negative potential with increasing the concentration of the mixed ions (Supplemental Materials Figure S4).

For the stability of CV profiles, we observed that the CV volume was decreased after electrodeposition by the amperometry, compared with the initial CV, attributed to deposition of the Ln (III) ions present in the electrolyte (Supplemental Materials Figure S5a). In other words, the concentration of the Ln (III) ions in the electrolyte was decreased. It was observed that the CV volume was gradually decreased with increasing the CV cycles (Supplemental Materials Figure S5b), attributed to the deposition process as mentioned above. The CV volume of the electrodeposited material was also gradually decreased (Supplemental Materials Figure S5c). The film became gradually removed from the surface and hydrogen bubble was created by a hydrogen evolution reaction and some were trapped on the surface (Supplemental Materials Figure S5d).

Figure 2 shows the SEM images of the electrodeposited mixed Ln + Eu over TiNS-SiTpy electrodes. It was clearly seen that thick overlayers were formed on the electrode, compared with the electrode before deposition (Figure 2a,a1). Optical microscope images (Figure 2n1 and the Supplemental Materials Figure S6) clearly showed electrodeposited overlayers. The corresponding photos (Supplemental Materials Figure S6) of the electrodeposited electrodes showed a clear discrimination between the undeposited and deposited areas. For electrodeposited La + Eu, nanowire morphology was observed, while others showed stacked films and particulate morphologies. From $\mathrm{Ce}+\mathrm{Eu}$ to $\mathrm{Gd}+\mathrm{Eu}$ (from Figure $2 \mathrm{c}$ to Figure 2h), stacked film morphology was observed. On the other hand, particulate morphology started to appear from $\mathrm{Tb}+\mathrm{Eu}$ (Figure 2i). Similar behavior (morphology change from film to particle with increasing the atomic number) was also observed for the electrodeposition on plain Ti electrodes [28]. Electrodeposition was also performed with TiNS electrodes in a $10 \mathrm{mM} \mathrm{Ln}$ (III)/0.1 $\mathrm{M} \mathrm{NaClO}_{4}$ electrolyte. The corresponding SEM and the optical microscope images are provided in the Supplemental Materials Figure S6a,b. Similar morphological change and clear deposition of the Ln elements were observed. 


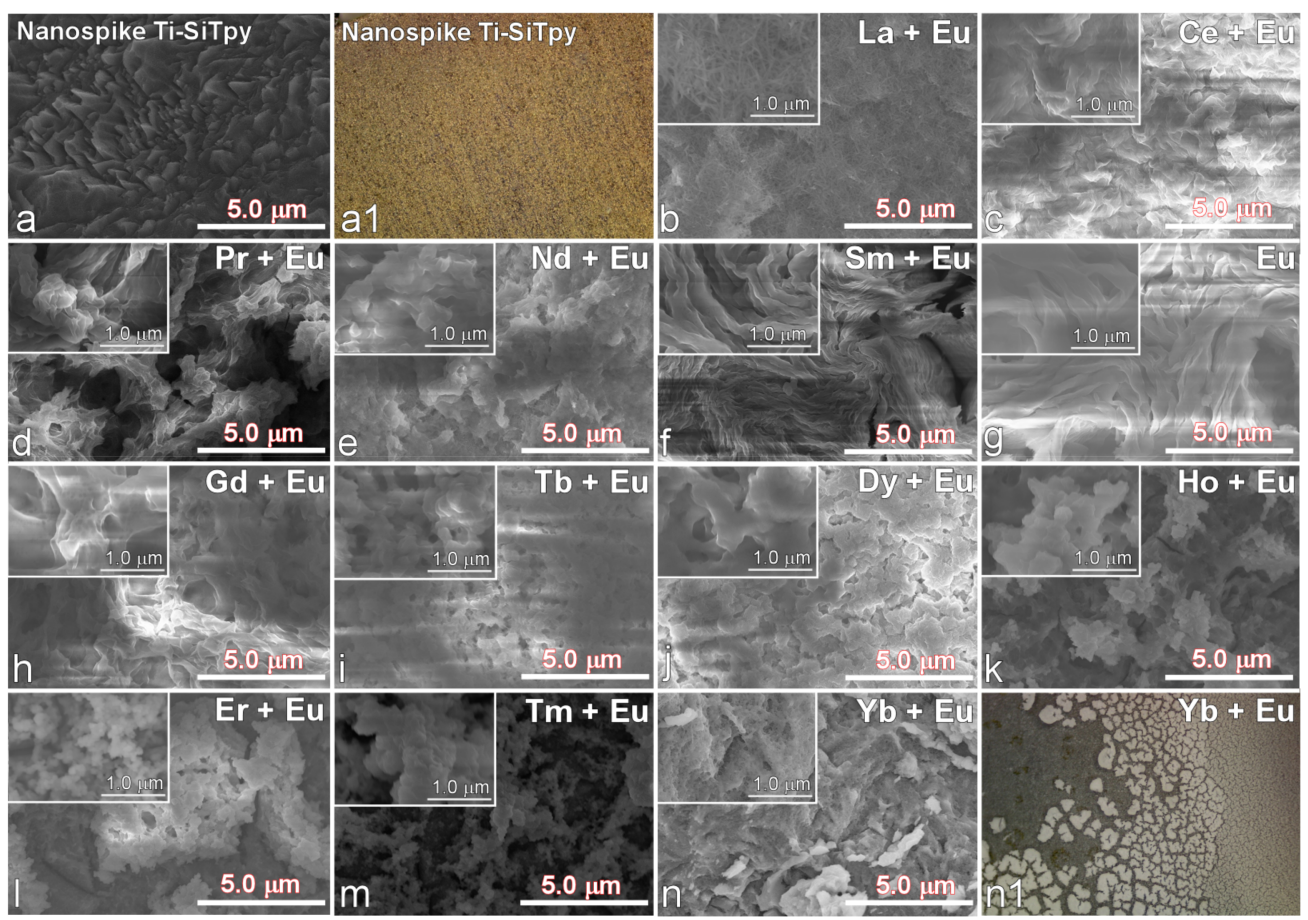

Figure 2. SEM (scanning electron microscope) images (a-n) of electrodeposited mixed Ln over TiNSSiTpy electrodes in a $5 \mathrm{mM} \mathrm{Eu}$ (III) $+5 \mathrm{mM} \mathrm{Ln} \mathrm{(III)} / 0.1 \mathrm{M} \mathrm{NaClO}_{4}$ electrolyte at an applied potential observed in the corresponding CV, and selected optical microscope images $(300 \times)$ for TiNS-SiTpy (a1) and electrodeposited mixed $\mathrm{Yb}+\mathrm{Eu}$ on a nanospike electrode (n1), and insets show the magnified image of the corresponding SEM image.

Characterization of the electrodeposited samples was performed by EDXS to examine and confirm the presence of Ln elements and other elements such as oxygen and carbon. Figure 3a shows the EDXS profiles of electrodeposited Ln on TiNS-SiTpy electrodes prepared in a $10 \mathrm{mM} \mathrm{Ln}$ (III)/0.1 $\mathrm{M} \mathrm{NaClO}_{4}$ electrolyte. Figure $3 \mathrm{~b}$ showed the EDXS profiles of electrodeposited $\mathrm{Eu}$ (red line), $\mathrm{Eu}+\mathrm{Gd}$ (pink line) and $\mathrm{Eu}+\mathrm{Tb}$ (green shaded line) on TiNS-SiTpy electrodes in a $5 \mathrm{mM} \mathrm{Eu}$ (III) + $5 \mathrm{mM} \mathrm{Ln} \mathrm{(III)} / 0.1 \mathrm{M} \mathrm{NaClO}_{4}$ electrolyte. It was very clear that the Ln elements were detected based on the Ln M and Ln L signals, whose positions were linearly shifted to a high energy with increasing the atomic number [29]. The EDXS for Pm element was omitted because of radioactivity and prohibition. However, the Pm M and Pm L signal positions could be predicted from Figure 3a. For the La element (atomic no. = 57), La M signals were observed at $0.63 \mathrm{KeV}$ and $0.84 \mathrm{KeV}$. The La L signals appeared at $4.67 \mathrm{KeV}, 4.93 \mathrm{KeV}$, and $5.38 \mathrm{KeV}$. For $\mathrm{Yb}$ element (atomic no. = 70), $\mathrm{Yb} \mathrm{M}$ signals were observed at $1.18 \mathrm{KeV}$ and $1.51 \mathrm{KeV}$. The $\mathrm{Yb} \mathrm{L}$ signals appeared at $7.41 \mathrm{KeV}$, 8.39 KeV, and $8.75 \mathrm{KeV}$. The Ln M and Ln L peak positions are summarized in Table 1.

The several other peaks at $0.26 \mathrm{keV}, 0.39 \mathrm{KeV}$, and $0.52 \mathrm{KeV}$ were attributed to $\mathrm{C} \mathrm{K}, \mathrm{N}$ $\mathrm{K}$, and $\mathrm{O} \mathrm{K}$ signals, respectively [29]. The $\mathrm{Ti} \mathrm{K}_{\alpha}$ and $\mathrm{Ti} \mathrm{K}_{\beta}$ signals (from the Ti support) were observed at $4.5 \mathrm{KeV}$ and $4.93 \mathrm{KeV}$, respectively. A Cl K signal was also significantly observed at $2.63 \mathrm{KeV}$, attributed to trapped or complexed $\mathrm{ClO}_{4}$ ion. The presence of $\mathrm{ClO}_{4}$ ion was also confirmed by FT-IR spectroscopy below. For the EDXS of mixed Eu + Gd (pink line) and $\mathrm{Eu}+\mathrm{Tb}$ (green shaded line) on TiNS-SiTpy electrodes (Figure 3b), mixed Ln L and Ln M signals were observed, indicating that two Ln elements were co-electrodeposited. The elemental atomic \% ratios of $\mathrm{Gd} / \mathrm{Eu}$ and $\mathrm{Tb} / \mathrm{Eu}$ were estimated to be 5.66\% / 6.34\% and $8.41 \% / 10.96 \%$, respectively (Supplemental Materials, Table S1). The co-deposition was also confirmed by XPS data, discussed below. EDXS elemental mapping images were obtained for the three selected samples (Supplemental Materials Figure S7). On the basis of the data, it was concluded that $\mathrm{Gd}$ and $\mathrm{Eu}$ (or $\mathrm{Tb}$ and $\mathrm{Eu}$ ) were both uniformly deposited on the electrodes. 
Complex formation and major functional groups were examined by taking FT-IR spectra of the electrodeposited samples. Figure $4 \mathrm{a}, \mathrm{b}$ show the transmittance FT-IR spectra of electrodeposited $\mathrm{Ln}$ and mixed Eu + Gd (pink line) and Eu + Tb (green line) on TiNSSiTpy electrodes, respectively. All the FT-IR profiles were observed to be very similar, indicating that all the electrodeposited materials had a similar metal complex. A strong and broad peak was commonly observed at $3590 \mathrm{~cm}^{-1}$, attributed to a stretching vibration of $\mathrm{OH}$ group. The corresponding bending vibration appeared at $1640 \mathrm{~cm}^{-1}$. Two strong peaks were observed between $1200 \mathrm{~cm}^{-1}$ and $1600 \mathrm{~cm}^{-1}$ (shaded areas) and assigned to stretchings of both $\mathrm{CO}_{3}{ }^{2-}$ and $\mathrm{NO}_{3}{ }^{-}$groups [30,31]. A strong peak was also observed at $1080 \mathrm{~cm}^{-1}$, assigned to the vibration of $\mathrm{ClO}_{4}{ }^{2-}$ ion [32]. A broad peak around $600 \mathrm{~cm}^{-1}$ was plausibly due to a Ln-O vibrational mode [33,34]. On the basis of the FT-IR data, it was concluded that the electrodeposited materials had $\mathrm{OH} / \mathrm{H}_{2} \mathrm{O}, \mathrm{CO}_{3}{ }^{2-}, \mathrm{NO}_{3}{ }^{-}$, and $\mathrm{ClO}_{4}{ }^{2-}$ groups with Ln-O bondings. The deduced complex was further discussed below, with the aid of XRD data.

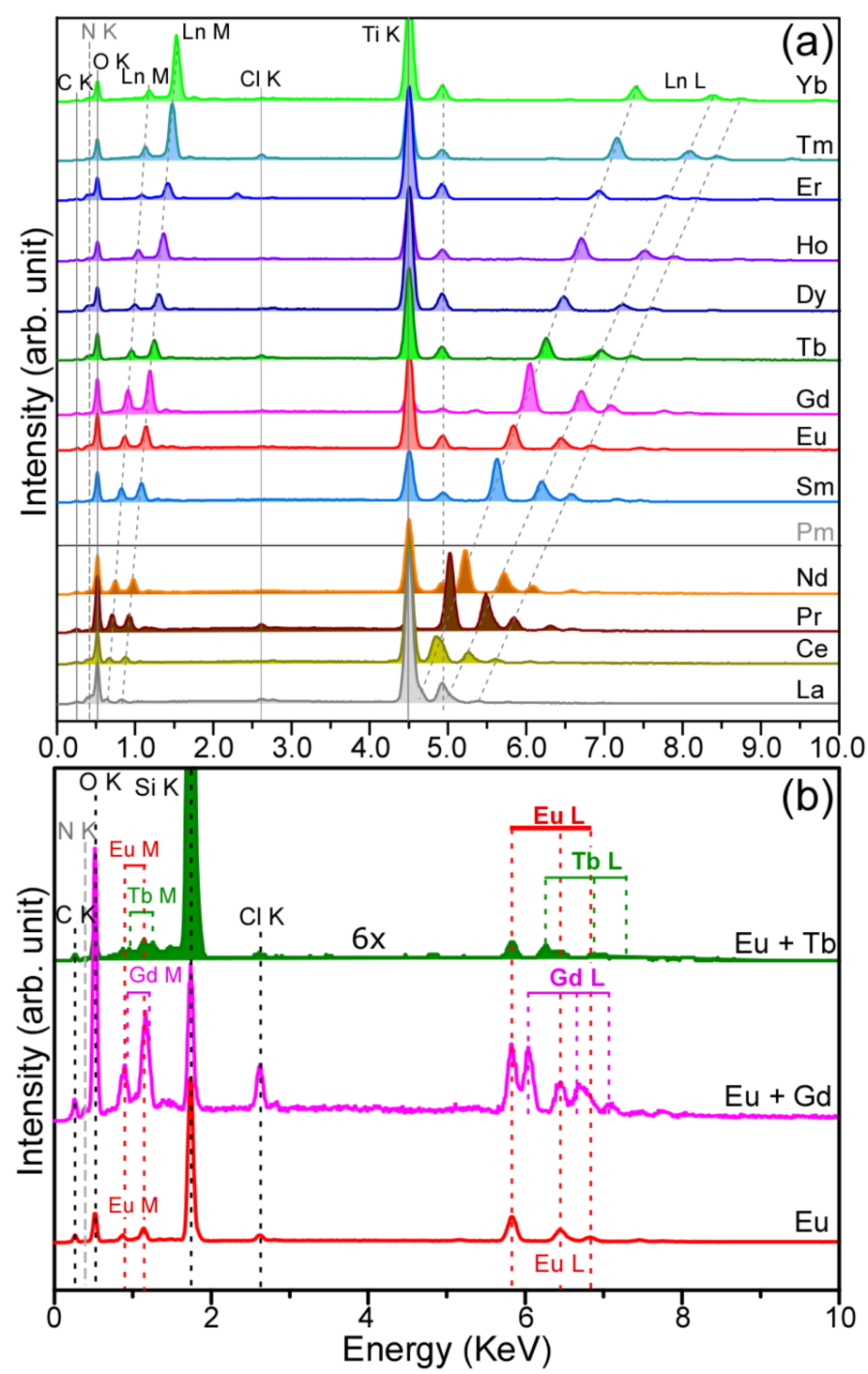

Figure 3. EDXS (energy dispersive X-ray spectroscopy) profiles of electrodeposited Ln (a) and electrodeposited $\mathrm{Eu}(\mathbf{b}$, red line), $\mathrm{Eu}+\mathrm{Gd}(\mathbf{b}$, pink line), and $\mathrm{Eu}+\mathrm{Tb}$ (b, green shaded line) on TiNS-SiTpy electrodes. Si K signal was due to Si substrate for mounting electrodeposited materials. 
Table 1. EDXS (energy dispersive X-ray spectroscopy) Ln M and Ln L peak positions (KeV taken in $0.01 \mathrm{keV}$ step).

\begin{tabular}{ccc}
\hline Ln & Ln $\mathbf{M}(\mathbf{K e V})$ & Ln L $(\mathbf{K e V})$ \\
\hline $\mathrm{La}$ & $0.63,0.84$ & $4.67,4.93,5.38$ \\
\hline $\mathrm{Ce}$ & $0.67,0.88$ & $4.87,5.27,5.61$ \\
\hline $\mathrm{Pr}$ & $0.71,0.92$ & $5.03,5.49,5.85$ \\
\hline $\mathrm{Nd}$ & $0.75,0.99$ & $5.23,5.72,6.09$ \\
\hline $\mathrm{Sm}$ & $0.82,1.09$ & $5.64,6.2,6.57$ \\
\hline $\mathrm{Eu}$ & $0.88,1.15$ & $5.83,6.47,6.84$ \\
\hline $\mathrm{Gd}$ & $0.92,1.20$ & $6.05,6.72,7.11$ \\
\hline $\mathrm{Tb}$ & $0.95,1.25$ & $6.25,6.97,7.36$ \\
\hline $\mathrm{Dy}$ & $1.01,1.31$ & $6.49,7.26,7.63$ \\
\hline $\mathrm{Ho}$ & $1.05,1.36$ & $6.72,7.51,7.88$ \\
\hline $\mathrm{Er}$ & $1.09,1.42$ & $6.93,7.79,8.17$ \\
\hline
\end{tabular}

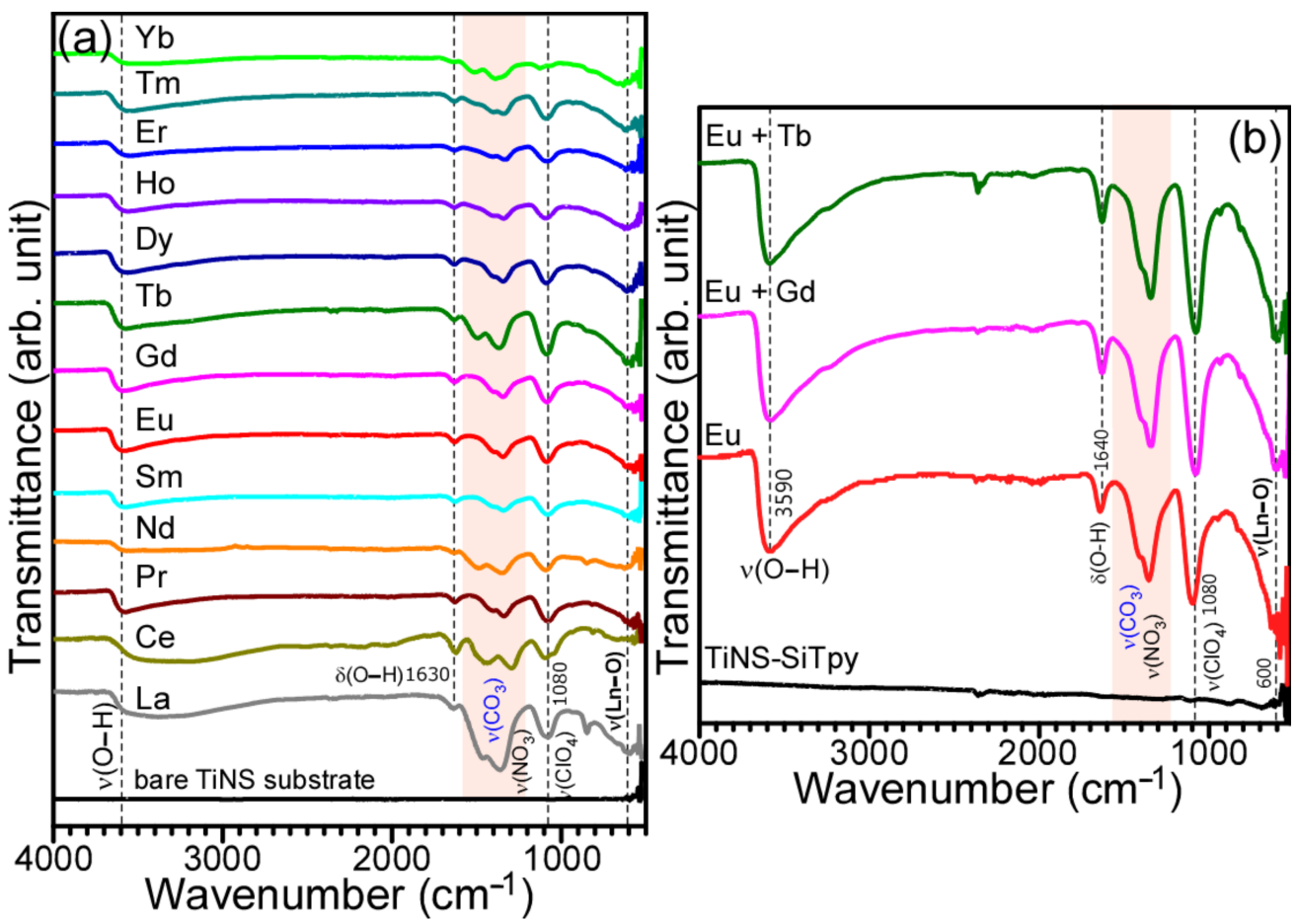

Figure 4. Transmittance FT-IR (Fourier-transform infrared) spectra of electrodeposited Ln (a) and electrodeposited $\mathrm{Eu}(\mathbf{b}$, red line), $\mathrm{Eu}+\mathrm{Gd}(\mathbf{b}$, pink line), and $\mathrm{Eu}+\mathrm{Tb}(\mathbf{b}$, green line) on TiNSSiTpy electrodes.

The crystal phase of the electrodeposited materials was examined by taking XRD. In Figure 5a, a TiNS-SiTpy electrode (before electrodeposition) shows XRD diffraction peaks at $2 \theta=35^{\circ}, 39^{\circ}, 40.0^{\circ}, 53.0^{\circ}$, and $63^{\circ}$, attributed to the (010), (002), (011), (012), and (110) crystal planes of hexagonal Ti (JCPDS 98-004-4872), respectively [28]. The XRD patterns were the same as those of bare TiNS. For the XRD patterns of electrodeposited Eu (Figure 5b), Eu + Gd (Figure 5c), and Eu + Tb (Figure 5d) on TiNS-SiTpy electrodes, four broad peaks (green shaded regions) were newly and clearly appeared around $2 \theta=10^{\circ}, 20^{\circ}, 29^{\circ}$, and $50^{\circ}$. All the electrodeposited materials showed very similar XRD profiles. In addition, very similar XRD profiles were also reported for electrodeposited Ln (III) species prepared in an unmixed $\mathrm{Ln}$ (III)/0.1 $\mathrm{M} \mathrm{NaClO}_{4}$ electrolyte over diverse 
electrodes [21-23,28]. These results are in good agreement with the FT-IR profiles that showed very similar for the three samples of electrodeposited $\mathrm{Eu}, \mathrm{Eu}+\mathrm{Gd}$, and $\mathrm{Eu}+\mathrm{Tb}$ on TiNS-SiTpy electrodes. On the basis of these similar XRD patterns and the previously reported literature [21-23,30], it was concluded that the electrodeposited materials had a complex of $\mathrm{Ln}_{2}(\mathrm{OH}) \cdot\left(\mathrm{NO}_{3}\right)_{\mathrm{y}-\mathrm{z}}\left(\mathrm{CO}_{3}\right)_{\mathrm{y}-\mathrm{z}}\left(\mathrm{ClO}_{4}\right)_{\mathrm{z}} \cdot \mathrm{nH}_{2} \mathrm{O}$ complex [21-23,30]. Joo et al. also reported very similar XRD profiles for electrodeposited Ln materials on $\mathrm{Ni}$ and carbon sheet substrates and assigned a similar complex formula [21-23,30]. The crystal planes of the four broad peaks are shown on the corresponding peaks [30].

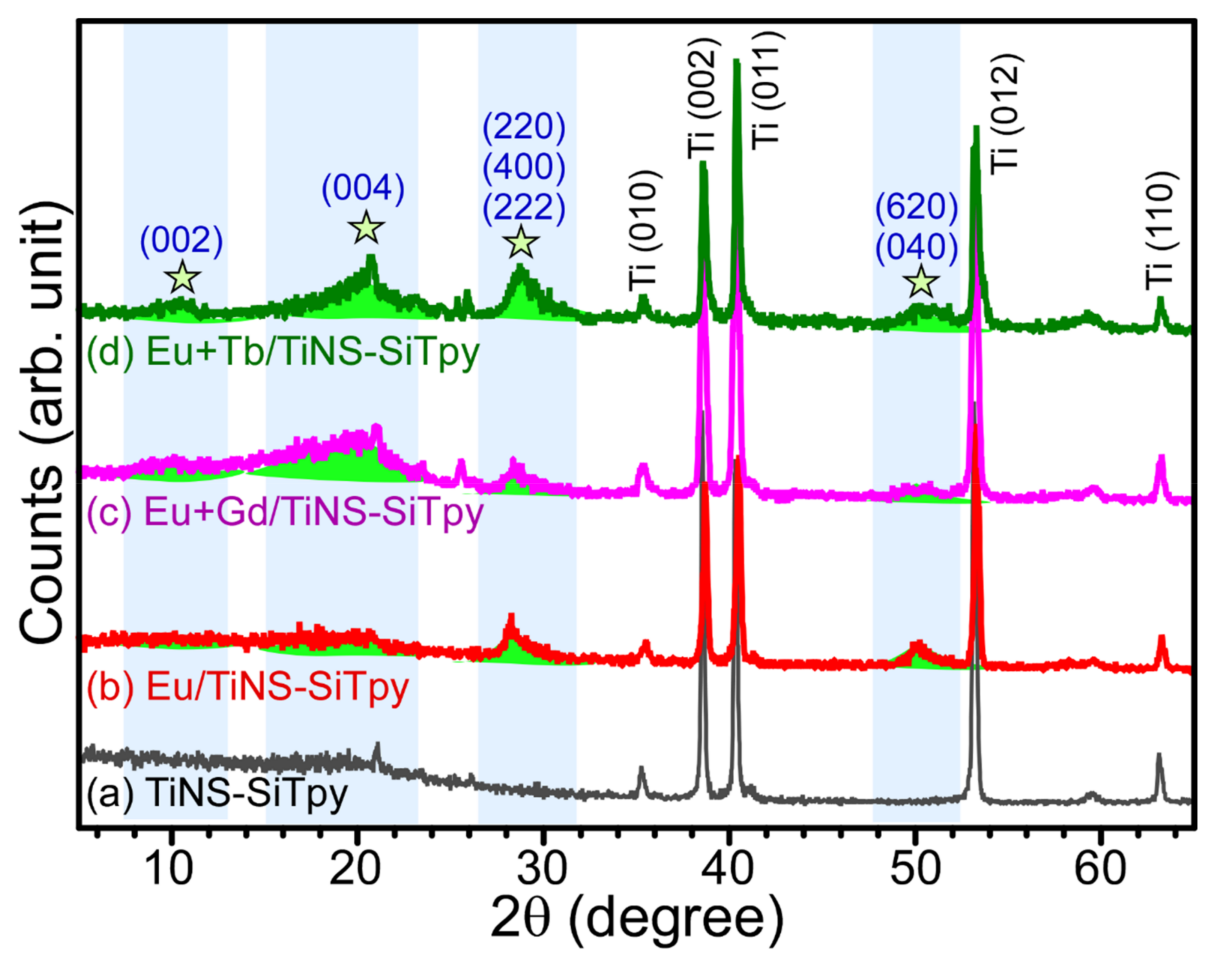

Figure 5. XRD (X-ray diffraction) profiles for bare (a, gray line), electrodeposited Eu (b, red line), Eu $+\mathrm{Gd}$ (c, pink line), and Eu + Tb (d, green line) on TiNS-SiTpy electrodes. Green shaded areas and star symbol indicate the major XRD peak positions of the complex.

The chemical states of the electrodeposited materials were examined by XPS (Figure 6). For the XPS of electrodeposited $\mathrm{Eu}$ (red line), $\mathrm{Eu}+\mathrm{Gd}$ (pink line), and $\mathrm{Eu}+\mathrm{Tb}$ (green line) on TiNS-SiTpy electrodes, the survey profiles (Figure 6a) commonly show $\mathrm{Eu}, \mathrm{Ti}, \mathrm{O}$, and $\mathrm{C}$ elements. All the binding energies were not referenced and a charging effect may be slightly involved in the spectra. For the high resolution Eu 3d XPS profiles (Figure 6b), Eu element was commonly detected, as expected, and the Eu $3 d_{3 / 2}$ and Eu $3 d_{5 / 2}$ peaks were observed at $1166.2 \mathrm{eV}$ and $1136.5 \mathrm{eV}$, respectively, with a spin-orbit splitting energy of $29.7 \mathrm{eV}$, assigned to Eu (III) oxidation state [25,35]. Two smaller peaks around $1157 \mathrm{eV}$ and $1127 \mathrm{eV}$ could be assigned to the Eu $3 d_{3 / 2}$ and Eu $3 d_{5 / 2}$ peaks of Eu (II) oxidation sate [25,35]. This indicates that $\mathrm{Eu}$ (II)-O species were possibly deposited in the reduction region. The ratio of $\mathrm{Eu}(\mathrm{III}) / \mathrm{Eu}$ (II) peaks was estimated to be $14 \times$ and $11 \times$ for electrodeposited Eu (red line) and Eu + Gd (pink line) on the electrodes, respectively. For the Tb $3 \mathrm{~d}$ XPS profile of electrodeposited $\mathrm{Eu}+\mathrm{Tb}$ (green line) on TiNS-SiTpy electrode (Figure $6 \mathrm{c}$ ), the $\mathrm{Tb} 3 \mathrm{~d}_{3 / 2}$ and $\mathrm{Tb} 3 \mathrm{~d}_{5 / 2}$ peaks were observed at $1277.1 \mathrm{eV}$ and $1242.5 \mathrm{eV}$, respectively, with a spin-orbit splitting energy of $34.6 \mathrm{eV}$, attributed to $\mathrm{Tb}$ (III) oxidation state [21,33,35]. For the $\mathrm{Gd} 3 \mathrm{~d}$ XPS profile of electrodeposited Eu + Gd (green line) on TiNS-SiTpy electrode (Figure 6d), the $\mathrm{Gd} 3 \mathrm{~d}_{3 / 2}$ and $\mathrm{Gd} 3 \mathrm{~d}_{5 / 2}$ peaks were positioned at $1220.4 \mathrm{eV}$ and $1188.1 \mathrm{eV}$, respectively, with a spin-orbit splitting energy of $32.3 \mathrm{eV}$, attributed to $\mathrm{Gd}$ (III) oxidation state [22,34,35]. 

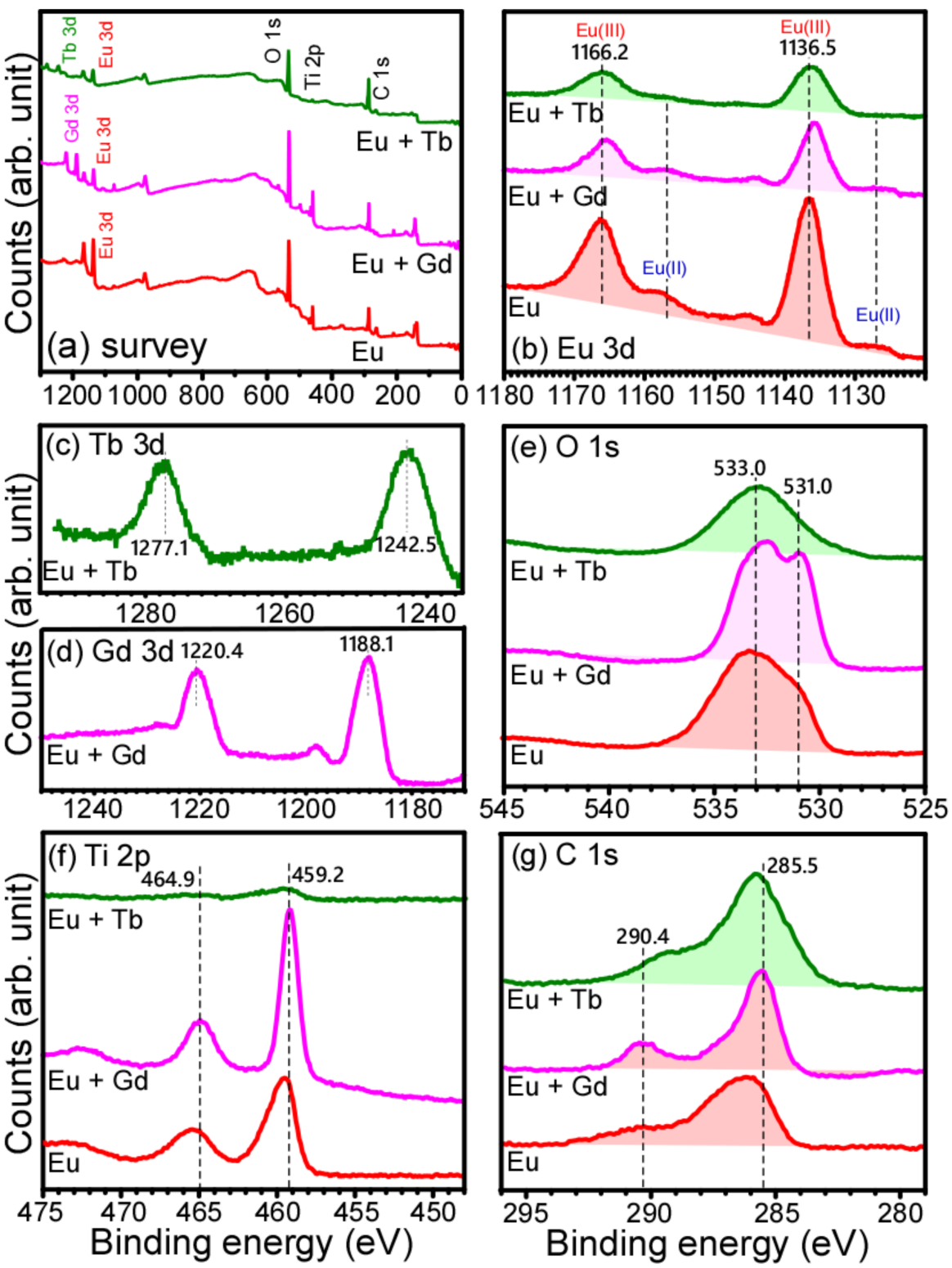

Figure 6. Survey (a), Eu 3d (b), Tb 3d (c), Gd 3d (d), O 1s (e), Ti 2p (f), and C 1s (g) XPS spectra for electrodeposited $\mathrm{Eu}$ (red line), $\mathrm{Eu}+\mathrm{Gd}$ (pink line) and $\mathrm{Eu}+\mathrm{Tb}$ (green line) on TiNS-SiTpy electrodes.

For the Ti $2 \mathrm{p}$ XPS profiles (Figure $6 \mathrm{f}$ ), Ti $2 \mathrm{p}_{1 / 2}$ and Ti $2 \mathrm{p}_{3 / 2}$ XPS peaks were commonly observed at BEs of around $464.9 \mathrm{eV}$ and $459.2 \mathrm{eV}$, respectively, with a spin-orbit splitting of $5.7 \mathrm{eV}$. This was attributed to Ti (IV) oxidation state [36,37]. For the O 1s XPS profiles, two broad regions were observed at $531.0 \mathrm{eV}$ and $533.0 \mathrm{eV}$. The lower BE peak was attributed to the lattice oxygen of Ti-O and/or Ln-O [36,37]. The higher BE peak was assigned to surface/complex species of $\mathrm{OH} / \mathrm{H}_{2} \mathrm{O}$ and defects $[36,37]$. The $\mathrm{C} 1$ s peaks commonly showed two broad regions around $290.4 \mathrm{eV}$ and $285.5 \mathrm{eV}$. The lower BE peak was due to $\mathrm{C}-\mathrm{C}$ species, while the higher BE peak was plausibly due to C-O species such as carbonates $[21,33,35]$.

Figure 7a displays the photoluminescence (PL) emission spectra of electrodeposited mixed Eu + Ln on TiNS-SiTpy electrodes at an excitation wavelength of $395 \mathrm{~nm}$. The $395 \mathrm{~nm}$ light matches the ${ }^{5} \mathrm{~L}_{6} \leftarrow{ }^{7} \mathrm{~F}_{0}$ (ground state) transition energy of $\mathrm{Eu}$ (III) ion. It was quite interesting that the electrodeposited $\mathrm{Eu}, \mathrm{Eu}+\mathrm{Gd}$, and $\mathrm{Eu}+\mathrm{Tb}$ samples showed strong emission signals, while other PL emission signals were very weak. Several sharp peaks were observed and attributed to the ${ }^{5} \mathrm{D}_{0} \rightarrow{ }^{7} \mathrm{~F}_{\mathrm{J}}$ transitions [25,38]; ${ }^{5} \mathrm{D}_{0} \rightarrow{ }^{7} \mathrm{~F}_{0}(578.5 \mathrm{~nm})$, ${ }^{5} \mathrm{D}_{0} \rightarrow{ }^{7} \mathrm{~F}_{1}(587.2 \mathrm{~nm}, 594.6 \mathrm{~nm}),{ }^{5} \mathrm{D}_{0} \rightarrow{ }^{7} \mathrm{~F}_{2}(612.6 \mathrm{~nm}, 615.4 \mathrm{~nm}, 619.2 \mathrm{~nm}$, and $623.1 \mathrm{~nm})$, ${ }^{5} \mathrm{D}_{0} \rightarrow{ }^{7} \mathrm{~F}_{3}(649.3 \mathrm{~nm}$ and $653.6 \mathrm{~nm})$, and ${ }^{5} \mathrm{D}_{0} \rightarrow{ }^{7} \mathrm{~F}_{4}(686.8 \mathrm{~nm}, 691.9 \mathrm{~nm}, 699.4 \mathrm{~nm}$, and 
$703.4 \mathrm{~nm}$ ). Several peaks for each ${ }^{5} \mathrm{D}_{0} \rightarrow{ }^{7} \mathrm{~F}_{\mathrm{J}}$ transition were attributed to the $2 \mathrm{~J}+1$ sublevel splittings under crystal field potential. For the 2D/3D-photoluminescence mapping profiles of the selected electrodeposited Eu (Figure 7b,b1), Eu + Gd (Figure 7c,c1), and Eu + Tb (Figure $7 \mathrm{~d}, \mathrm{~d} 1$ ) samples, the dense regions are mainly at an excitation wavelength of $395 \mathrm{~nm}$, corresponding to the ${ }^{5} \mathrm{~L}_{6} \leftarrow{ }^{7} \mathrm{~F}_{0}$ transition energy [25]. The ${ }^{5} \mathrm{D}_{0} \rightarrow{ }^{7} \mathrm{~F}_{\mathrm{J}}$ transition regions were also quite densely spaced. On the basis of the PL profiles, it could be concluded that characteristic emission of $\mathrm{Eu}$ (III) ion was active when $\mathrm{Gd}$ (III) and $\mathrm{Tb}$ (III) ions were mixed. Furthermore, Gd (III) ion improved the emission of Eu (III) compared with that of electrodeposited $\mathrm{Eu}$.
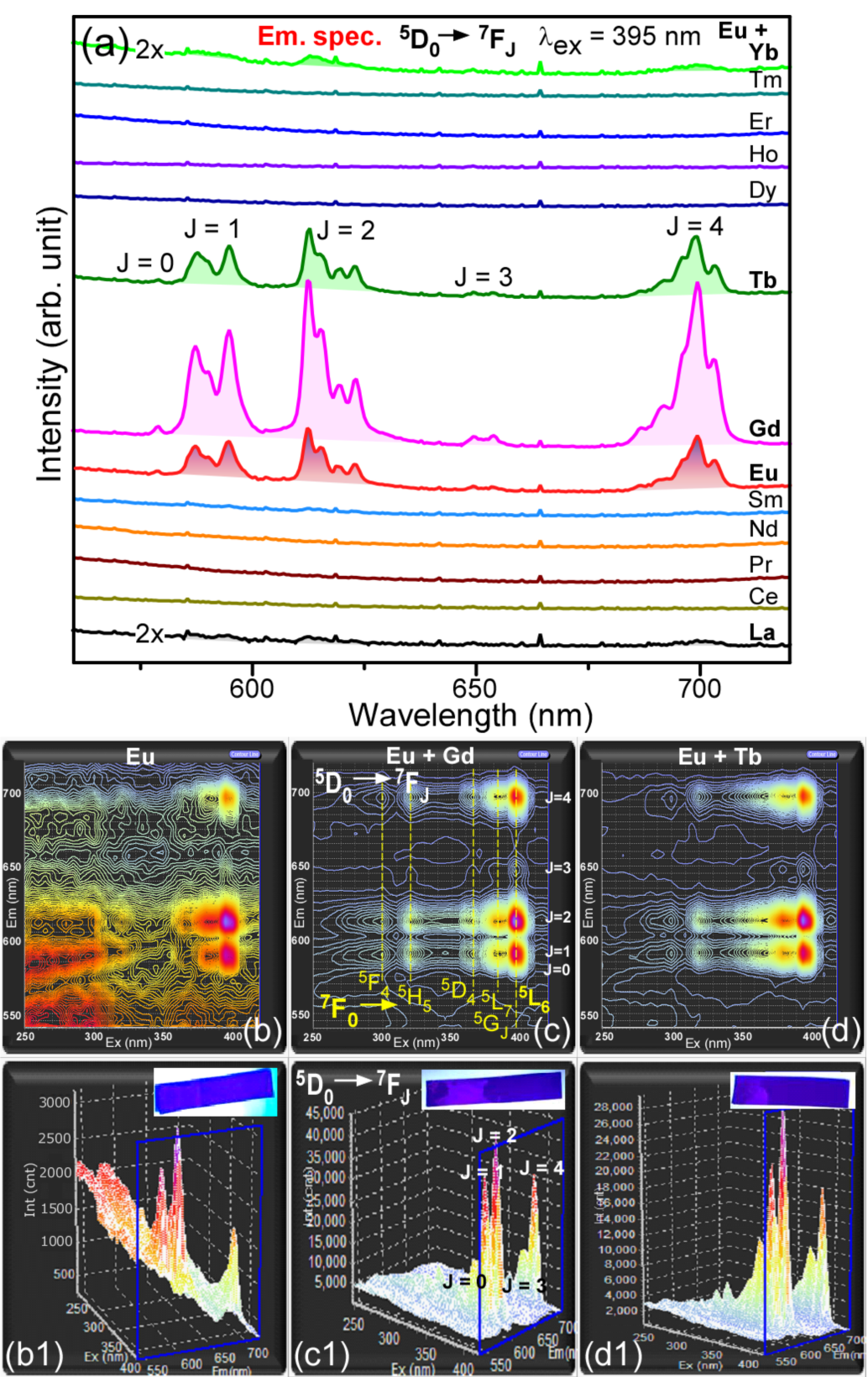

Figure 7. Emission spectra (a) of electrodeposited mixed Eu + Ln on TiNS-SiTpy electrodes and the selected 2D/3D-photoluminescence mapping profiles for electrodeposited $\mathrm{Eu}(\mathbf{b}$ and $\mathbf{b} \mathbf{1}), \mathrm{Eu}+\mathrm{Gd}$ (c and $\mathbf{c 1})$, and $\mathrm{Eu}+\mathrm{Tb}$ (d and $\mathbf{d 1})$. Inset photos show the corresponding samples under UV light.

Photoluminescence decay kinetics were evaluated for the selected electrodeposited $\mathrm{Eu}, \mathrm{Eu}+\mathrm{Gd}$ and $\mathrm{Eu}+\mathrm{Tb}$ samples, and the PL decay curves are displayed in Figure 8. 
The PL emission line was fixed at $610 \mathrm{~nm}$, corresponding to the ${ }^{5} \mathrm{D}_{0} \rightarrow{ }^{7} \mathrm{~F}_{2}$ transition. A third-order exponential decay function was used and the consequent fitting parameters are summarized in Table 2. The average lifetimes were measured to be $0.12 \mu \mathrm{s}, 1.32 \mu \mathrm{s}$, and $1.03 \mu \mathrm{s}$ for the $\mathrm{Eu}, \mathrm{Eu}+\mathrm{Gd}$, and $\mathrm{Eu}+\mathrm{Tb}$ samples, respectively. The $\mathrm{Eu}+\mathrm{Gd}$ sample showed the longest lifetime. As a consequent result, the strongest PL emission signal was observed for the $\mathrm{Eu}+\mathrm{Gd}$ sample shown in Figure 7 above.

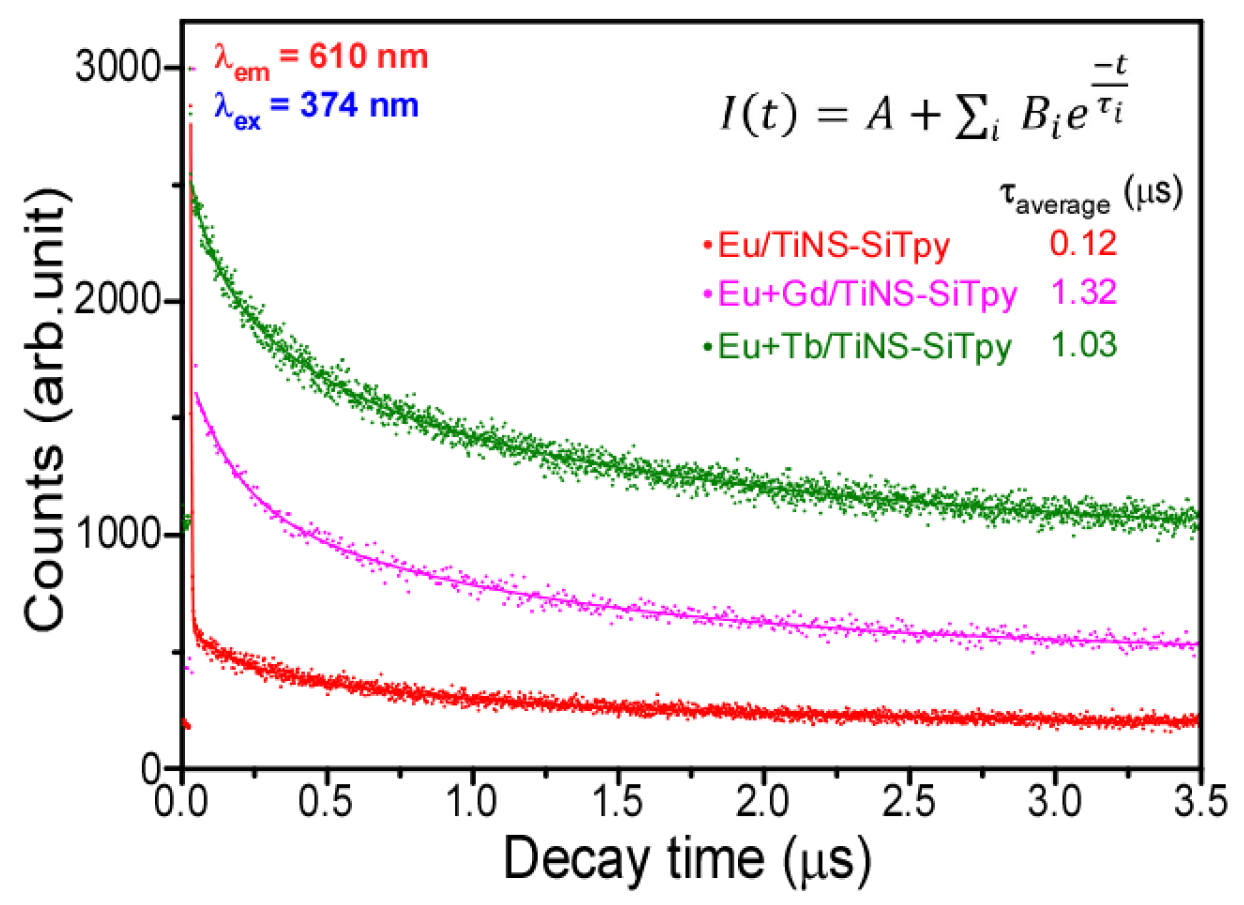

Figure 8. PL (photoluminescence) decay curves at $610 \mathrm{~nm}$ emission line at an excitation wavelength of $374 \mathrm{~nm}$ for electrodeposited Eu (red dots), Eu + Gd (pink dots), and Eu + Tb (green dots).

Table 2. Fitting parameters of the PL (photoluminescence) decay curves in Figure 8 for electrodeposited $\mathrm{Eu}, \mathrm{Eu}+\mathrm{Gd}$, and $\mathrm{Eu}+\mathrm{Tb}$ on TiNS-SiTpy electrodes.

\begin{tabular}{cccc}
\hline Parameters $^{*}$ & Eu/TiNS-SiTpy & Eu + Gd/TiNS-SiTpy & Eu + Tb/TiNS-SiTpy \\
\hline$\tau_{1}(\mu \mathrm{s})$ & 0.14601 & 0.92757 & 0.37351 \\
\hline$\tau_{2}(\mu \mathrm{s})$ & 1.08873 & 4.52343 & 1.92062 \\
\hline$\tau_{3}(\mu \mathrm{s})$ & 0.00232 & 0.15218 & 0.07966 \\
\hline $\mathrm{B}_{1}$ & 142.7179 & 529.1066 & 545.0598 \\
\hline $\mathrm{B}_{2}$ & 258.5388 & 225.3185 & 721.3731 \\
\hline $\mathrm{B}_{3}$ & 2167.448 & 441.1102 & 303.7022 \\
\hline $\mathrm{R}_{1}$ & 0.05556 & 0.442569 & 0.347142 \\
\hline $\mathrm{R}_{2}$ & 0.100649 & 0.188467 & 0.459434 \\
\hline $\mathrm{R}_{3}$ & 0.84379 & 0.368965 & 0.193424 \\
\hline $\mathrm{A}$ & 192.6185 & 412.9804 & 1.0383885 \\
\hline$\chi^{2}$ & 1.04538 & 1.04873 & $1.02747( \pm 0.0825)$ \\
\hline$\tau_{\text {average }}(\mu \mathrm{s})$ & $0.11965( \pm 0.0366)$ & $1.31918( \pm 0.163)$ & \\
\hline \multirow{2}{*}{$A+\sum_{i} B_{i} e^{\frac{-t}{\tau_{i}}}, R_{i}=B_{i} /\left(\sum_{i=1}^{3} B_{i}\right), \tau_{\text {average }}=\sum_{i=1}^{3} R_{i} \cdot \tau_{i}, \mathrm{R}=$ the relative ratio factor. } &
\end{tabular}




\section{Conclusions}

To further understand the electrochemistry of lanthanide ions, electrochemical tests of cyclic voltammetry and amperometry were performed using TiNS-SiTpy electrodes for $\mathrm{Ln}(\mathrm{La}, \mathrm{Ce}, \mathrm{Pr}, \mathrm{Nd}, \mathrm{Sm}, \mathrm{Eu}, \mathrm{Gd}, \mathrm{Tb}, \mathrm{Dy}, \mathrm{Ho}, \mathrm{Er}, \mathrm{Tm}$, and $\mathrm{Yb}$ ) ions and mixed $\mathrm{Eu}$ (III) + Ln (III) ions in a $0.1 \mathrm{M} \mathrm{NaClO}_{4}$ electrolyte. Electrodepositions of the single and mixed Ln ions were successfully performed on the functionalized Ti nanospike electrodes. The physicochemical properties of the electrodeposited materials were fully examined by SEM, XRD, EDXS, FT-IR, XPS, PL, and PL decay kinetics. On the basis of XRD and FT-IR profiles, the electrodeposited materials had a similar complex structure of $\mathrm{Ln}_{2}(\mathrm{OH}) \cdot\left(\mathrm{NO}_{3}\right)_{\mathrm{y}-\mathrm{z}}\left(\mathrm{CO}_{3}\right)_{\mathrm{y}-\mathrm{z}}\left(\mathrm{ClO}_{4}\right)_{\mathrm{z}} \cdot \mathrm{nH}_{2} \mathrm{O}$. EDXS confirmed the electrodeposited Ln elements, the composition of the mixed Ln elements, and the elements of the functional groups. XPS further confirmed the oxidation states of the Ln elements. PL emission signals were strongly observed for electrodeposited $\mathrm{Eu}, \mathrm{Eu}+\mathrm{Gd}$, and $\mathrm{Eu}+\mathrm{Tb}$ samples. The emission signals were assigned to the ${ }^{5} \mathrm{D}_{0} \rightarrow{ }^{7} \mathrm{~F}_{\mathrm{J}(=0,1,2,3,4)}$ transitions of $\mathrm{Eu}$ (III) ions. The PL lifetimes were measured to be $0.12 \mu \mathrm{s}, 1.32 \mu \mathrm{s}$, and $1.03 \mu$ s for the Eu, Eu + Gd, and Eu + $\mathrm{Tb}$ samples, respectively. It was observed that $\mathrm{Tb}$ and $\mathrm{Gd}$ enhanced the PL emission, while other Ln ions negated the emission signal of $\mathrm{Eu}$ (III) ions. Tb and Gd additions exhibited longer lifetimes.

The present unique results can provide very useful information on lanthanide (display) material designs, electrochemical application tests, electrochemical recovery for recovery from wastes, and other Ln-related material understanding.

Supplementary Materials: The following are available online at https:/ /www.mdpi.com/article/10 $.3390 /$ met11060977/s1, Figure S1: Cyclic voltammetry profiles in a $10 \mathrm{mM} \mathrm{Ln} \mathrm{(III)/0.1} \mathrm{M} \mathrm{NaClO}_{4}$ electrolyte over bare TiNS electrodes; Figure S2: Cyclic voltammetry profiles in a $10 \mathrm{mM} \mathrm{Ln}$ (III) $/ 0.1 \mathrm{M}$ $\mathrm{NaClO}_{4}$ electrolyte over TiNS-SiTpy electrodes; Figure S3: Selected superimposed cyclic voltammetry profiles; Figure S4: Selected superimposed cyclic voltammetry profiles; Figure S5: CV profiles and a photo; Figure S6: SEM and the corresponding optical microscope $(300 \times)$ images; Figure S7: EDXS elemental mapping images; Table S1: EDXS elemental atomic composition ratios (\%).

Author Contributions: M.H.J., S.J.P., H.J.J., S.-M.H., Y.S. and C.K.R.; methodology, M.H.J., S.J.P., H.J.J., S.-M.H., Y.S. and C.K.R.; validation, M.H.J., S.J.P., H.J.J. and S.-M.H.; formal analysis, M.H.J. and S.J.P.; investigation, Y.S.; resources, M.H.J.; data curation, Y.S.; writing-original draft preparation, Y.S. and C.K.R.; writing-review and editing, H.J.J. and Y.S.; visualization, Y.S. and C.K.R.; supervision, Y.S. and C.K.R.; project administration, Y.S. All authors have read and agreed to the published version of the manuscript.

Funding: This research was funded by a National Research Foundation of Korea (NRF) grant funded by the Ministry of Education, Science, and Technology, Korea (2018M2B2A9065523). The APC was funded by the NRF grant.

Institutional Review Board Statement: Not applicable.

Informed Consent Statement: Not applicable.

Data Availability Statement: The data presented in this study are available in the article and Supplementary Material here.

Conflicts of Interest: The authors declare no conflict of interest.

\section{References}

1. Ricci, P.C. Assessment of crystalline materials for solid state lighting applications: Beyond the rare earth elements. Crystals 2020, 10, 559. [CrossRef]

2. Monteiro, J.H.S.K. Recent Advances in Luminescence Imaging of Biological Systems Using Lanthanide (III) Luminescent Complexes. Molecules 2020, 25, 2089. [CrossRef]

3. Gontcharenko, V.E.; Kiskin, M.A.; Dolzhenko, V.D.; Korshunov, V.M.; Taydakov, I.V.; Belousov, Y.A. Mono- and Mixed Metal Complexes of $\mathrm{Eu}^{3+}, \mathrm{Gd}^{3+}$, and $\mathrm{Tb}^{3+}$ with a Diketone, Bearing Pyrazole Moiety and CHF2-Group: Structure, Color Tuning, and Kinetics of Energy Transfer between Lanthanide Ions. Molecules 2021, 26, 2655. [CrossRef] 
4. Tigaa, R.A.; Ortega, R.E.; Lin, X.; Strouse, G.F. A Versatile Tripodal Ligand for Sensitizing Lanthanide (LnIII) Ions and Color Tuning. Chemistry 2021, 3, 138-145. [CrossRef]

5. Kaya, E.E.; Kaya, O.; Stopic, S.; Gürmen, S.; Friedrich, B. NdFeB Magnets Recycling Process: An Alternative Method to Produce Mixed Rare Earth Oxide from Scrap NdFeB Magnets. Metals 2021, 11, 716. [CrossRef]

6. Choi, E.-Y.; Jeong, S.M. Electrochemical processing of spent nuclear fuels: An overview of oxide reduction in pyroprocessing technology. Prog. Nat. Sci. 2015, 25, 572-582.

7. Khan, M.M.; Ansari, S.A.; Pradhan, D.; Han, D.H.; Lee, J.; Cho, M.H. Defect-induced band gap narrowed $\mathrm{CeO}_{2}$ nanostructures for visible light activities. Ind. Eng. Chem. Res. 2014, 53, 9754-9763.

8. Vita, A. Catalytic Applications of CeO2-Based Materials. Catalysts 2020, 10, 576. [CrossRef]

9. Zou, F.-R.; Wang, S.-N.; Wang, F.-F.; Liu, D.; Li, Y. Synthesis of Lanthanide-Functionalized Carbon Quantum Dots for Chemical Sensing and Photocatalytic Application. Catalysts 2020, 10, 833. [CrossRef]

10. Kim, D. Recent Developments in Lanthanide-Doped Alkaline Earth Aluminate Phosphors with Enhanced and Long-Persistent Luminescence. Nanomaterials 2021, 11, 723. [CrossRef]

11. Bejan, D.; Bahrin, L.G.; Shova, S.; Marangoci, N.L.; Kökçam-Demir, Ü.; Lozan, V.; Janiak, C. New Microporous Lanthanide Organic Frameworks. Synthesis, Structure, Luminescence, Sorption, and Catalytic Acylation of 2-Naphthol. Molecules 2020, 25, 3055. [CrossRef]

12. Bazhenova, T.A.; Yakushev, I.A.; Lyssenko, K.A.; Maximova, O.V.; Mironov, V.S.; Manakin, Y.V.; Kornev, A.B.; Vasiliev, A.N.; Yagubskii, E.B. Ten-Coordinate Lanthanide [Ln (HL)(L)] Complexes (Ln = Dy, Ho, Er, Tb) with Pentadentate N3O2-Type Schiff-Base Ligands: Synthesis, Structure and Magnetism. Magnetochemistry 2020, 6, 60. [CrossRef]

13. Hernández-Fuentes, C.; Ruiz-Guerrero, R.; Morales-Ramírez, A.d.J.; Molina-Maldonado, P.; Medina-Velazquez, D.Y. New Mononuclear Complex of Europium (III) and Benzoic Acid: From Synthesis and Crystal Structure Solution to Luminescence Emission. Crystals 2020, 10, 674. [CrossRef]

14. Lu, P.; Wang, Y.; Huang, L.; Lian, S.; Wang, Y.; Tang, J.; Belfiore, L.A.; Kipper, M.J. Tb ${ }^{3+} / \mathrm{Eu}^{3+}$ Complex-Doped Rigid Nanoparticles in Transparent Nanofibrous Membranes Exhibit High Quantum Yield Fluorescence. Nanomaterials 2020, 10, 694. [CrossRef]

15. Kim, S.; Lee, S.-H. Electrochemical Properties of $\mathrm{NdCl}_{3}$ and $\mathrm{CeCl}_{3}$ in $\mathrm{Molten} \mathrm{LiCl}-\mathrm{KCl}$ Eutectic Salt. Appl. Sci. $2020,10,7252$. [CrossRef]

16. Song, K.; Yu, H.; Zhang, J.; Bai, Y.; Guan, Y.; Yu, J.; Guo, L. Rosebengal-Loaded Nanoporous Structure Based on Rare Earth Metal-Organic-Framework: Synthesis, Characterization and Photophysical Performance. Crystals 2020, 10, 185. [CrossRef]

17. Fan, X.; Gu, L.; Hu, Y.; Zhu, Q. Uniform Spheres of $\alpha-\mathrm{NaYF}_{4}: \mathrm{RE}^{3+}(\mathrm{RE}=\mathrm{Eu}, \mathrm{Tb}, \mathrm{Ce}, \mathrm{Er}$, and Tm): Template-Free Synthesis, Multi-Color Photoluminescence, and Their Application in Cellular Imaging. Crystals 2020, 10, 119. [CrossRef]

18. Cavalli, E. Development and Applications of Transition Metal or Rare Earth-Based Luminescent Inorganic Materials. Crystals 2020, 10, 1120. [CrossRef]

19. Ahn, N.-K.; Swain, B.; Shim, H.-W.; Kim, D.-W. Recovery of rare earth oxide from waste NiMH batteries by simple wet chemical valorization process. Metals 2019, 9, 1151. [CrossRef]

20. Cardoso, C.E.D.; Almeida, J.C.; Lopes, C.B.; Trindade, T.; Vale, C.; Pereira, E. Recovery of rare earth elements by carbon-based nanomaterials-A review. Nanomaterials 2019, 9, 814. [CrossRef]

21. Joo, M.H.; Park, S.J.; Hong, S.-M.; Rhee, C.K.; Kim, D.; Sohn, Y. Electrodeposition and Characterization of Lanthanide Elements on Carbon Sheets. Coatings 2021, 11, 100. [CrossRef]

22. Joo, M.H.; Park, S.J.; Jang, H.J.; Hong, S.-M.; Rhee, C.K.; Sohn, Y. Enhanced Photoluminescence of Electrodeposited Europium Complex on Bare and Terpyridine-Functionalized Porous Si Surfaces. Photochem 2021, 1, 38-52. [CrossRef]

23. Joo, M.H.; Park, S.J.; Hong, S.M.; Rhee, C.K.; Sohn, Y. Electrochemical Recovery and Behaviors of Rare Earth (La, Ce, Pr, Nd, Sm, $\mathrm{Eu}, \mathrm{Gd}, \mathrm{Tb}, \mathrm{Dy}, \mathrm{Ho}, \mathrm{Er}, \mathrm{Tm}$, and $\mathrm{Yb}$ ) Ions on Ni Sheets. Materials 2020, 13, 5314. [CrossRef] [PubMed]

24. Sahoo, J.; Jaiswar, S.; Chatterjee, P.B.; Subramanian, P.S.; Jena, H.S. Mechanistic Insight of Sensing Hydrogen Phosphate in Aqueous Medium by Using Lanthanide (III)-Based Luminescent Probes. Nanomaterials 2021, 11, 53. [CrossRef] [PubMed]

25. Kang, J.-G.; Jung, Y.; Min, B.-K.; Sohn, Y. Full characterization of $\mathrm{Eu}(\mathrm{OH})_{3}$ and $\mathrm{Eu}_{2} \mathrm{O}_{3}$ nanorods. Appl. Surf. Sci. 2014, 314, 158-165. [CrossRef]

26. Park, S.J.; Joo, M.H.; Hong, S.-M.; Rhee, C.K.; Kang, J.-G.; Sohn, Y. Electrochemical Eu (III)/Eu (II) Behaviors and Recovery over Terpyridyl-Derivatized Modified Indium Tin Oxide Electrode Surfaces. Chem. Eng. J. 2021, 15, 128717. [CrossRef]

27. Park, S.J.; Joo, M.H.; Hong, S.-M.; Kang, J.-G.; Rhee, C.K.; Lee, S.W.; Sohn, Y. Electrochemical Eu (III) behaviors and Eu oxysulfate recovery over terpyridine-functionalized indium tin oxide electrode. Inorg. Chem. Front. 2020, 8, 1175-1188. [CrossRef]

28. Joo, M.H.; Park, S.J.; Hong, S.M.; Rhee, C.K.; Sohn, Y. Electrochemical behaviors and electrodeposited materials of lanthanides ( $\mathrm{La}, \mathrm{Ce}, \mathrm{Pr}, \mathrm{Nd}, \mathrm{Sm}, \mathrm{Eu}, \mathrm{Gd}, \mathrm{Tb}, \mathrm{Dy}, \mathrm{Ho}, \mathrm{Er}, \mathrm{Tm}$, and $\mathrm{Yb}$ ) on terpyridine-functionalized Ti sheets. Mater. Today Commun. 2021, 27, 102305. [CrossRef]

29. NIST DTSA-II Software. Available online: https:/ / cstl.nist.gov/div837/837.02/epq/dtsa2/ (accessed on 1 May 2021).

30. Wu, X.; Li, J.-G.; Zhu, Q.; Liu, W.; Li, J.; Li, X.; Sun, X.; Sakka, Y. One-step freezing temperature crystallization of layered rare-earth hydroxide $\left(\mathrm{Ln}_{2}(\mathrm{OH})_{5} \mathrm{NO}_{3} \cdot \mathrm{nH}_{2} \mathrm{O}\right)$ nanosheets for a wide spectrum of $\mathrm{Ln}(\mathrm{Ln}=\mathrm{Pr}-\mathrm{Er}$, and $\mathrm{Y})$, anion exchange with fluorine and sulfate, and microscopic coordination probed via photoluminescence. J. Mater. Chem. C 2015, 3, 3428-3437. [CrossRef]

31. Millero, F.J.; Magdalena Santana-Casiano, J.; Gonzalez-Davila, M. The formation of Cu (II) complexes with carbonate and bicarbonate ions in $\mathrm{NaClO} 4$ solutions. J. Solut. Chem. 2010, 39, 543-558. [CrossRef] 
32. Chen, Y.; Zhang, Y.-H.; Zhao, L.-Z. ATR-FTIR spectroscopic studies on aqueous $\mathrm{LiClO}_{4}, \mathrm{NaClO}_{4}$, and $\mathrm{Mg}\left(\mathrm{ClO}_{4}\right)_{2}$ solutions. Phys. Chem. Chem. Phys. 2004, 6, 537-542. [CrossRef]

33. Sohn, Y. Structural and spectroscopic characteristics of terbium hydroxide/oxide nanorods and plates. Ceram. Int. 2014, 40, 13803-13811. [CrossRef]

34. Kang, J.-G.; Min, B.-K.; Sohn, Y. Synthesis and characterization of $\mathrm{Gd}(\mathrm{OH})_{3}$ and $\mathrm{Gd}_{2} \mathrm{O}_{3}$ nanorods. Ceram. Int. 2015, 41, 1243-1248. [CrossRef]

35. NIST X-ray Photoelectron Spectroscopy Database, Version 4.1 National Institute of Standards and Technology, Gaithersburg. 2012. Available online: http:/ / srdata.nist.gov/xps/ (accessed on 5 May 2021).

36. Kang, J.-G.; Sohn, Y. Interfacial nature of Ag nanoparticles supported on TiO2 photocatalysts. J. Mater. Sci. 2012, 47, 824-832. [CrossRef]

37. Yang, J.H.; Park, S.J.; Rhee, C.K.; Sohn, Y. Photocatalytic CO2 Reduction and Electrocatalytic H2 Evolution over Pt (0,II,IV)-Loaded Oxidized Ti Sheets. Nanomaterials 2020, 10, 1909. [CrossRef] [PubMed]

38. Pawlik, N.; Szpikowska-Sroka, B.; Pisarski, W.A. Energy transfer study on Tb3+/Eu3+ co-activated sol-gel glass-ceramic materials containing MF3 (M = Y, La) nanocrystals for NUV optoelectronic devices. Materials 2020, 13, 2522. [CrossRef] 